\title{
CAR-SHARING: THE IMPACT ON METROPOLITAN SPATIAL STRUCTURES
}

\author{
Piotr Marek Smolnicki ${ }^{1}$, Jacek Soltys ${ }^{2}$
}

\begin{abstract}
Many examples from the past show how new technologies, designed to solve particular problems, can create new problems as a side-effect. Some unforeseen or unwanted results may influence the use of space and spatial structures, for example. Car-sharing is an invention that competes with car ownership and which can drastically rise the efficiency of car use and reduce the number of vehicles per users. Diffusion of car-sharing will accelerate in the near future. The spatial consequences of a car-ownership-oriented-century are already known. However, the complications of all travelers using shared automobiles is yet to be understood. It is therefore appropriate to anticipate and prepare for potential side effects of this innovation's diffusion and thus avoid possible negative consequences. This reasoning has led to our research into the relationship between modern mobility innovations and metropolitan spatial structures. The earliest implementations of new transport technologies appeared in metropolises, which also have the highest level of general mobility. This article presents the assumptions and principles from scenario-based research. The example shows how diffusion of this innovation determine possible scenarios relating to future impacts of car-sharing on spatial structures.
\end{abstract}

UDC Classification: 656.1 DOI: http://dx.doi.org/10.12955/cbup.v4.858

Keywords: automobile ownership, car-sharing, metropolitan spatial structures, urban planning.

\section{Introduction}

Many examples from the past show that new technologies, designed to solve particular problems, can also create side effects that become the new problems (Smolnicki, 2014). This paradox inspired a broader research problem about the impact of modern technologies on spatial structures (Smolnicki, 2015). It led to an open PhD Course about "Relations Between Emerging Mobility Technologies and Metropolitan Spatial Structures". This article presents part of this research, which examines the spatial impact of the emerging mobility service known as "car-sharing". While the spatial side effect of automobile ownership over the last century is already known, this article attempts to answer the question of whether car-sharing services can mitigate or develop unwanted automobile-related spatial consequences. Today, around the world there are numerous car-sharing fleets enabling people to "pick-up" a car from the street. The following sections include a literature review of the relevant research about car-sharing services throughout the world. The article presents and discusses the research results regarding possible consequences of car-sharing on metropolitan (urban and suburban) spatial structures. This research uses a scenario method to identify future impacts. The results of each scenario are evaluated, and the optimal scenario main lines highlighted. Further research on the topic is recommended.

\section{Literature Review}

The car-sharing idea has been continuously developing in Europe since the first post-war years (Neckermann, 2015, loc. 190, Shaheen \& Cohen, 2013, pp. 5-7). Shaheen, Chan, Bansal, \& Cohen (2015, p. 20) defined car-sharing as "a program where individuals have temporary access to a vehicle without the costs and responsibilities of ownership", and divided it into three categories: one-way, round-trip, and personal peer-to-peer (P2P). Vehicles can be found on the street at either the final destination place of the last user, dedicated charging stations for electric vehicles (EV's), or through dedicated applications connecting service participants, i.e. users and car owners. Car-sharing is more efficient in densely populated urban areas (Rupprecht Consult - Forschung \& Beratung GmbH, 2013, p. 4), and when directly available, e.g. in peoples' neighborhoods (Bundesverband CarSharing, 2015). It is estimated that one shared car can replace four up to as many as twenty-three cars, depending on various local conditions; Badger, 2013, p. 184; Ceille, 2015; Neckermann, 2015, loc. 1640; Shaheen \& Cohen, 2013, p. 9). Therefore, car-sharing is responsible for reduction in car sales, with the trend likely to continue (Schwartz \& Rosen, 2015, loc. 1431). Massachusetts Institute of Technology (MIT) research has shown that 80 per cent reduction in cars can be achieved by combining rides and car-

\footnotetext{
${ }^{1}$ Piotr Marek Smolnicki, Department of Urban Design and Regional Planning, Faculty of Architecture, Gdańsk University of Technology, Gdańsk, Poland, piotr.smolnicki@pg.gda.pl

${ }^{2}$ Jacek Sołtys, Department of Urban Design and Regional Planning, Faculty of Architecture, Gdańsk University of Technology, Gdańsk, Poland, jsoltys@pg.gda.pl
} 
sharing (Ratti \& Claudel, 2015). This phenomenon is due to millennials caring little about ownership, including car ownership (Gao, Hensley, \& Zielke, 2014). The average rental time of different carsharing services throughout the world is between thirty and seventy minutes, depending on local conditions (Neckermann, 2015, loc. 1684). While station-based system cars are more populated, the free-floating car-sharing systems are more popular (Bundesverband CarSharing, 2015).

Many original equipment manufacturers (OEMs) of the automotive industry are developing driverless vehicles and at the same time, investing in car-sharing and similar mobility services (Bertoncello \& Wee, 2015). Vehicle manufacturers, together with their suppliers, technology entities, and researchers are developing driverless, self-driving transport, i.e. connected and fully autonomous vehicles (CAVs; Lander et al., 2016, pp. 9-10). Car-sharing is not for everyday rides in large suburbs (Castor, 2015), but the question remains: will driverless-car-sharing change this predicament? It is estimated that, due to automation, vehicle sales will continue to grow, but with urban rather than suburban and regional areas as the main type of segmentation (Mohr, Kaas, Gao, Wee, \& Möller, 2016, pp. 4-5). Moreover, the MIT Media Lab study shows that shared driverless mobility in dense urban areas can eliminate all parking requirements with the possibility of exchanging single parking bays with higher functional uses equal to a few dwellings (Lander et al., 2016, pp. 9-10; Larson, 2015). Lawrence Burns, the director of the Program on Sustainability, at Columbia University's Earth Institute, estimates that shared-driverless systems could offer customers about $90 \%$ savings compared to the costs of car ownership, while delivering a better experience (Mui \& Carroll, 2013, loc. 323). The Institute of Electronic Equipment Engineers (IEEE) estimated that driverless cars could account for up to 75 per cent of all cars by 2040 (Schwartz \& Rosen, 2015, loc. 3780). Cato Institute warns that transportation services are not prepared for car-sharing diffusion (Neckermann, 2015, loc. 1938). Some anticipate that public transit will disappear due to the driverless car-sharing (O'Toole, 2016). Self-driving cars do not require engagement of the traveler, therefore people who chose public transit for the opportunity of working while traveling instead of "wasting" time with driving can switch to autonomous automobiles (Sullican, 2015, loc. 201; Wadud, 2016, p. 2; Wayner, 2013, loc. 1095). Moreover, a few car-sharing fleets have already expanded into suburban areas (Shaheen \& Cohen, 2013, p. 6). This could promote the continuation of suburbanization, which in the future, car-sharing may not replace privately owned cars but complement them (Bundesverband CarSharing, 2015). In the case of driverless car-sharing, the time spent in vehicles traveling to suburbs could be used productively, and therefore suburbs could grow further. Moreover, it can be assumed that car-sharing may result in significant changes in spatial structures, depending on the method of introduction and distribution of these services. The future of the mobility industry depends on simultaneous competition and cooperation of competitors (Mohr et al., 2016, pp. 4-5). Therefore, we propose that markets together with the public sector will balance the use of each mode of urban transport, but with dependence on other factors, like the development of spatial structures.

\section{Methodology}

This research study was based on heuristic construction of scenarios. The use of scenarios is one of the most practical prognostic methods, especially where social and institutional behaviors play a crucial role (Chojnicki, 1988). The oldest and one of the best definitions of scenarios was formed by Kahn and Wiener (1967, cited in Torrieri \& Nijkamp, 2005), who defined the term as a possible, often hypothetical, sequence of events constructed in an internally consistent way for the purpose of focusing on causal processes and decision points. Durance \& Godet (2010, p. 1489) defined scenario as "a description (usually of a possible future) which assumes the intervention of several key events or conditions which will have taken place between the time of the original situation and the time in which the scenario is set". Among the types of scenarios distinguished by Ducot and Lubben (1980), descriptive exploratory scenarios are best for the subject of this described study.

In this article, each scenario presents the diffusion of car-sharing services and its impact on metropolitan (urban and suburban) spatial structures, i.e. physical structures of built environment, and spatial socio-economic configurations. The presented scenarios are general and therefore do not include detailed migrations between each mode of transport. The impact of emerging innovations and technologies, which can disrupt future mobility, is unpredictable, and not considered in this research. 
A few main features of scenarios may be assumed as rules of differentiating scenarios for car-sharing, e.g. differences in speed of diffusion, proportion of car-sharing in general mobility, and spatial spread. In the following research, two independent variables were assumed as rules of differentiating scenarios: the type of investor (based on three types presented in Figure 1) and choice of business model (from the three models presented in Figure 1). The status of these variables (rules of differentiating scenarios) being independent is an appropriate assumption in exploratory scenarios (Soltys, 2014). The abovementioned features of scenarios are dependent variables, and thus will emerge in results of the scenario building process. Therefore, it is possible that the main lines of two (or more) scenarios (Figure 1) may crossover or terminate at one point. Each scenario's assumed state of independent variables must be consistent with that of every other scenario. Therefore, Figure 1 presents eight main lines of consistent combinations. Inconsistent combinations were excluded (e.g. privatization of public car-sharing services).

\section{Results and Discussion}

Figure 1 presents multiple main lines of scenarios for car-sharing diffusion and its impact on metropolitan spatial structures, based on the fleet investment sectors and chosen business models. The users of the car-sharing service might involve both automobile owners and transit passengers, regardless of whether they had a driver's license or not. It was assumed for both, that car-sharing systems would convince more to obtain driver's license, and a greater number of car-sharing fleets would offer driverless vehicles. There was also a multiple number of factors that to convince travelers to seek a specific mode of transport and six levels represented the different scenario variables: (1) contemporary mobility segmentation, (2) investment sectors, (3) public expenses needed for introducing a project, (4) business model decisions, (5) future spatial impacts, and (6) future public expenses. The scenarios ended with one of three possible results. Car-sharing services rated somewhere between individually owned cars (around 400-600 vehicles per 1000 citizens, depending on location) and public transport (i.e. bus, light-rail, streetcar or tram). Car-sharing services could complement both car and public transport use. The possible investors for car-sharing fleets were private (i.e. car manufacturers, information and technology mobility service providers) and public (i.e. municipality or national transportation companies). One scenario was based on private-public participation (PPP) where the fleet owner could be a private or public, with infrastructure owned by the municipality, and services provided by the private sector, i.e. information and communications technology (ICT). A scenario based on fully private ownership-and-service generated zero to very little introduction expenses for the public sector. In the PPP scenario, the costs for the municipality could start from modest (i.e. costs in connecting EVs charging stations to the city's grid) to medium (i.e. cost in preparing parking bays with EVs charging stations and opening data integrated public transport and information systems with the car-sharing service). The public ownership scenario had the highest introduction costs for a municipality associated with buying the fleet, preparing infrastructure, and connecting and maintaining services. This scenario's costs could be reduced with a smaller scale implementation, but the municipality would need to consider the probable inefficiencies of a small scale service. ${ }^{3}$

The car-sharing fleet investor type also determined a business model. The market-related model would obviously need to be chosen by the private sector. Due to the appearance of a new comfortable mobility mode for non-car-owners, consequences may result in sub-urbanization and also deurbanization of central urban areas, the same as occurred in many cities with automobile domination and addiction (Davidow, 2015). The possible scenario was that the private investor will introduce carsharing services only in densely populated areas. In this scenario, spatial consequences could result, similar to the PPP based scenario. Public and PPP investment might determine decisions in both the "sustainable" and "city revival" model. The sustainable model considered both cost effectiveness and smart urbanization. This model was preferred for cities with equally developed and functioning spatial structures. Therefore, it would generate income without creating additional negative spatial consequences for metropolitan areas. For cities struggling with suburbanization and de-urbanization the city-revival model was preferred, but the system's efficiency needs to be considered, especial in

\footnotetext{
${ }^{3}$ The case of Helsinki's Kutsuplus on-demand bus service which worked until the end of 2015 and was hold due to high public costs before it could reach efficient share in all modes of transit (Sulopuisto, 2016).
} 
terms of having sufficient vehicles, accessibility to popular locations and routes, and the political willingness to subsidize the system with public funds.

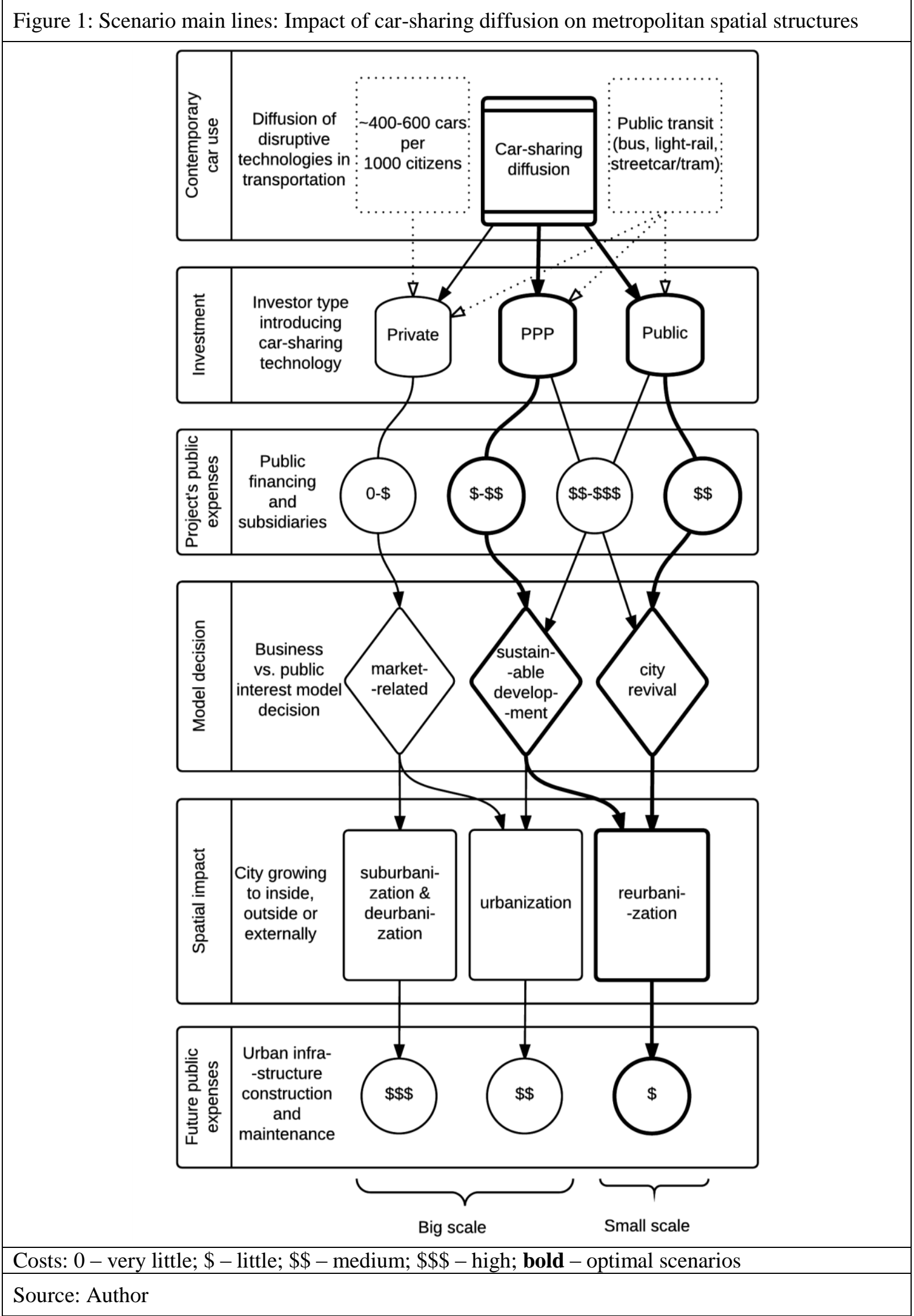


Each of the eight main lines of the presented scenarios finished with future indirect costs (Figure 1). Due to expansive infrastructure (underground, media, roads, and highways), construction and maintenance expenses for low density suburban areas (sprawl) in the private market-oriented model would generate high future indirect costs. ${ }^{4}$ Therefore, inner city citizens would be required to contribute to the city's edge infrastructure maintenance. The sustainable development scenario costs would be distributed equally. This scenario would be unjustified where the district's functions varied. In this case, the authors propose equity instead of equality. The scenario based on city revival would heal struggling districts, with generate low indirect costs in the future.

This research presented a simplified model of car-sharing diffusion. It assumed that car-sharing may result in significant changes in spatial structures, depending on the way in which it is introduced and choice of business model. The modeling ended with three alternative results. Suburbanization, with greater expenditure of money, is considered the least desirable for future common prosperity. The cost-efficient re-urbanization is considered the best outcome in this respect. There are two main ways for achieving this best result, as shown bolded on the diagram: PPP and public investment. Due to the proportion of investment costs with the PPP investment, the car-sharing diffusion may have a wider aerial scale and quantitative share, and therefore, may diffuse faster and more cost efficiently, whereas the public sector may have to direct its influence towards promoting equity over equality to reach the most positive outcome. The second bolded scenario is based on full public investment. Therefore, it has a smaller scale and may be located in areas of need, for example, where it is difficult to maintain a self-owned car, possibly due to a lack of or the high cost of parking space. In these areas, car-sharing may improve locals' mobility and reduce private car use, and therefore, lessen traffic and dedication of parking bays. The city revival business model would result in a better quality of life (more mobility options), lower costs of infrastructure maintenance (due to high functional density and use intensity), lower costs of mobility compared to car-ownership, and less waste of space (due to parking space reduction). Therefore, when planning the introduction of car-sharing, it may be important to focus on the assumed far reaching results.

\section{Conclusions}

The research objectives were met by answering the questions: how to manage the car-sharing diffusion for optimal results in the future and what are the approaches to avoid. It is essential to continue research into this subject before technological diffusion and possible side-effects become irreversible. In addition, this research should be repeated with new variables to check if the same answers will be achieved. The results should also be confirmed by multiple surveys: on experts (Delphi method), users from a representative space of a metropolitan area (e.g. citizens, students, tourists, and workers), and users of the already implemented car-sharing systems.

\section{Acknowledgement}

In above article, P.M. Smolnicki contributed the literature review and research of car-sharing scenarios, and Jacek Sołtys the methodology and supervision of content quality.

\section{References}

Badger, E. (2013). Share everything: Collaborative consumption arises from urbanization, and it's here to stay. In S. Mathis \& J. Cary (Eds.), TED Books. City 2.0. The Habitat of the Future and How to Get There. Ted Conferences (Original work published 2013-02-20).

Bertoncello, M., \& Wee, D. (2015). Ten ways autonomous driving could redefine the automotive world. Retrieved from McKinsey \& Company website: http://www.mckinsey.com/insights/automotive_and_assembly/ten_ways_autonomous_ driving_could_redefine_the_automotive_world

Bundesverband CarSharing e. V. (2015). 'Carsharing expands rapidly into new towns and communities'. Retrieved from $\mathrm{http} / / / \mathrm{www} . c a r s h a r i n g . d e / p r e s s e / p r e s s e m i t t e i l u n g e n / c a r s h a r i n g-e x p a n d s-r a p i d l y-i n t o-n e w-t o w n s-a n d-c o m m u n i t i e s-m o r e-$ than-25

Castor, E. (2015, November 12). Mobility and the Sharing Economy. MIT Media Lab. Disrupting Mobility Summit, Media Lab Building, Cambridge, MA. Retrieved from http://tinyurl.com/jumytmg

Ceille, K. (2015, November 12). Moving Beyond Disruption. MIT Media Lab. Disrupting Mobility Summit, Media Lab Building, Cambridge, MA. Retrieved from http://tinyurl.com/jumytmg

\footnotetext{
${ }^{4}$ There are also other indirect costs, i.e. sprawl-related diseases (diabetics, obesity, asthma, car-related injuries etc.) - Speck $(2013,531)$, transportation costs - Schwartz and Rosen $(2015,1520)$, food transport and storage costs - Frey and Yaneske (2007, pp. 86-87).
} 
Chojnicki, Z. (1988). Terytorialny system społeczny. In B. Jałowiecki (Ed.), Biuletyn KPZK PAN. Gospodarka przestrzenna, region, lokalność (138th ed., pp. 29-49). Warszawa: PAN.

Davidow, W. H. (2015). The Internet Has Been a Colossal Economic Disappointment. Retrieved from https://hbr.org/2015/03/the-internet-has-been-a-colossal-economic-disappointment\#signin

Ducot, G., \& Lubben, G. J. (1980). A typology for scenarios. Futures, 12(1), 51-57.

Durance, P., \& Godet, M. (2010). Scenario building: Uses and abuses. Technological Forecasting and Social Change, 77(9), 1488-1492. DOI:10.1016/j.techfore.2010.06.007

Frey, H., \& Yaneske, P. (2007). Visions of sustainability: Cities and regions. London, New York: Taylor \& Francis.

Gao, P., Hensley, R., \& Zielke, A. (2014). A road map to the future for the auto industry (McKinsey Quarterly). Retrieved from McKinsey \& Company website:

http://www.mckinsey.com/insights/manufacturing/a_road_map_to_the_future_for_the_auto_industry

Lander, E. S., Holdren, J. P., Press, W., Savitz, M., Austin, W. M., Chyba, C., Predith, A. (2016). Technology and the Future of Cities (Report to the President). Washington D.C. Retrieved from Executive Office of the President; President's Council of Advisors on Science and Technology (PCAST) website:

http://static1.squarespace.com/static/537a1f91e4b0ccfe943c6bc6/t/56d9fb4101dbaec85ef39fa0/1457126210525/WhiteHouse Report.pdf

Larson, K. (2015, November 11). Event Welcome and Keynote Session. MIT Media Lab. Disrupting Mobility Summit, Media Lab Building, Cambridge, MA. Retrieved from http://tinyurl.com/h4m2ws2

Mohr, D., Kaas, H.-W., Gao, P., Wee, D., \& Möller, T. (2016). Automotive revolution -perspective towards 2030: How the convergence of disruptive technology-driven trends could transform the auto industry (Advanced Industries).

Mui, C., \& Carroll, P. B. (2013). Driverless Cars: Trillions Are Up for Grabs (eBook; Kindle Edition) (Original work published March 2013).

Neckermann, L. (2015). The Mobility Revolution: Zero Emissions, Zero Accidents, Zero Ownership (eBook; Kindle Edition): Matador.

O’Toole, R. (2016). Transit is dead. Let's prepare for the next mobility revolution. Retrieved from https://www. washingtonpost.com/news/in-theory/wp/2016/03/01/transit-is-dead-lets-prepare-for-the-next-mobility-revolution/ Ratti, C., \& Claudel, M. (2015). Full speed ahead: How the driverless car could transform cities (Global Infrastructure Initiative). Retrieved from McKinsey \& Company website:

http://www.mckinsey.com/insights/sustainability/full_speed_ahead_how_the_driverless_car_could_transform_cities Rupprecht Consult - Forschung \& Beratung GmbH. (2013). Prospects for electric car sharing and use in small and medium cities and towns. Expert study on the state of the art (ELMOS). Cologne. Retrieved from Elmos website: http://www.elmosproject.eu/fileadmin/content/documents/Internal_reports_surveys_tenders/2013-11-

15_ELMOS_report_electric_car_sharing.pdf

Schwartz, S. I., \& Rosen, W. (2015). Street smart: The rise of cities and the fall of cars (First edition; eBook; Kindle Edition). New York: Public Affairs.

Shaheen, S. A., \& Cohen, A. P. (2013). Car sharing and Personal Vehicle Services: Worldwide Market Developments and Emerging Trends. International Journal of Sustainable Transportation, 7(1), 5-34. DOI:10.1080/15568318.2012.660103

Shaheen, S. A., Chan, N. D., Bansal, A., \& Cohen, A. P. (2015). Shared mobility: A sustainability \& technologies workshop: definitions, industry developments, and early understanding. Berkeley: Transportation Sustainability Research Center, University of California, Berkeley.

Smolnicki, P. M. (2014). Wplyw nowoczesnych technologii na przestrzeń publiczna. Esej [The impact of emerging technologies on public spaces. Essay], Gdańsk.

Smolnicki, P. M. (2015). The influence of modern technologies on spatial structures. In M. Czubenko \& M. Tatara (Eds.), BioTech Conference 2014. PhD Interdisciplinary Journal. Special Issue. BIOTech Conference 2014 ( $1^{\text {st }}$ ed., pp. 67-75).

Gdańsk: Gdansk University of Technology Press. Retrieved from http://sdpg.pg.gda.pl/pij/wp-

content/blogs.dir/133/files/2015/03/01_2015_07-smolnicki.pdf

Sołtys, J. (2014). Scenarios in Planning for Cities and Regions: Experiences and Problems. In O. Bina, L. Balula, \& A. Ricci (Eds.), Urban Futures - Squaring Circles. Europe, China and the World in 2050. Conference Proceedings. Institute of Social Sciences - University of Lisbon. Retrieved from http://www.ufsc2050.ics.ul.pt/papers/26.pdf

Speck, J. (2013). Walkable cities: Why redesigning our communities around walking is the best medicine. In S. Mathis \& J. Cary (Eds.), TED Books. City 2.0. The Habitat of the Future and How to Get There (521-636). Ted Conferences.

Sullican, P. (2015). Getting Ready for Driverless Cars: Everything you need to know to invest now in the companies developing the technology that will revolutionize the way we commute (eBook; Kindle Edition).

Sulopuisto, O. (2016). Why Helsinki's On-Demand Bus Service Failed: The publicly-funded foray into ridesharing pleased users but had trouble filling seats. Retrieved from http://www.citylab.com/commute/2016/03/helsinki-on-demand-busservice-kutsuplus/472545/

Torrieri, F., \& Nijkamp, P. (2005). Scenario analysis in spatial impact assessment: a methodological approach. In S. R. Curwell, M. Deakin, \& M. Symes (Eds.), Sustainable urban development ( $3^{\text {rd }}$ ed., pp. 43-61). London: Routledge.

Wadud, Z. (2016). Self-Driving Cars: Will they reduce energy use? (Mobility \& Energy Futures Series).

Wayner, P. C. (2013). Future Ride v2: 99 Ways the Self-Driving, Autonomous Car Will Change Everything from Buying Groceries to Teen Romance to Surviving a Hurricane to ... Home to Simply Getting from Here to There (Kindle edition; 2 edition). Future Ride: Create Space Independent Publishing Platform (Original work published Jul 8, 2013). 